\title{
Temperature Dependence of the Breaking Force of Kamaboko in the Puncture Test
}

\section{Short Paper}

\author{
Moritsugu Hamada* \\ (Received September 25, 1990)
}

Breaking functions such as breaking force, breaking strain, and jelly strength of Kamaboko usually serve as indices of the commercial quality of Kamaboko in Japan, and are available for basic research to elucidate the gelation mechanism of salt soluble fish proteins. ${ }^{1,2}$ Little attention, however, has so far been given to the effects of temperature on these functions.

The present paper reports the effects of temperature on the breaking force of Kamaboko in the range 10$80^{\circ} \mathrm{C}$, together with the effect of starch content on the relation of breaking force to temperature.

Three commercially available Kamaboko (A, B, and C) prepared from frozen raw fish meat paste of walleye pollack Theragra chalcogramma were used for the experiment. Kamaboko A had the highest quality, followed by $B$ and $C$, according to the scores of $a$ sensory test. The starch content of Kamaboko A determined by the conventional method ${ }^{3)}$ was $0.62 \%$

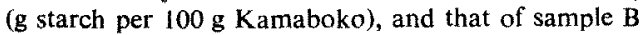
and $\mathrm{C}, 4.76 \%$ and $7.70 \%$, respectively. Consequently, the quality of Kamaboko was inversely proportional to starch content.

The Kamaboko sample was cut into pieces $3 \mathrm{~cm}$ in height, and the test pieces were immersed in a $2.5 \%$ $\mathrm{NaCl}$ solution for $15 \mathrm{~min}$ at a given temperature from 10 to $80^{\circ} \mathrm{C}$. Breaking force was measured under the same conditions as those under which the test pieces had been immersed in the solution, using an NRM2002J rheometer (Fudoh Kogyo Co., Japan). The plunger $5 \mathrm{~mm}$ in diameter was driven at a constant rate of $2 \mathrm{~cm} / \mathrm{min}$. Five test pieces were used for each measuring temperature for every Kamaboko sample.

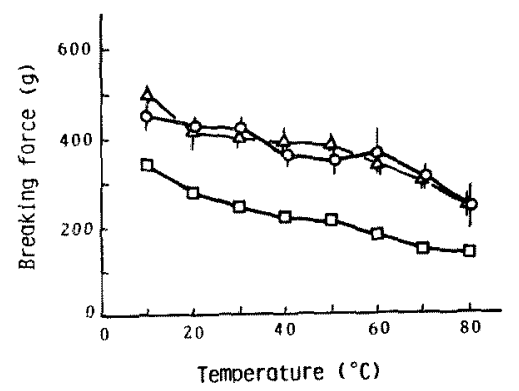

Fig. 1. Temperature dependences of the breaking force of Kamaboko $A(O), B(\triangle)$, and $C(D)$.

Starch content of Kamaboko; A, $0.62 \% \mathrm{~B}$, $4.76 \%$ C. $7.70 \%$ (grams starch/100 g Kamaboko). The vertical bars represent the mean \pm standard deviation.
The variation in the breaking force with a rise in temperature is shown in Fig. 1. The magnitude of the breaking forces of Kamaboko A and B was almost the same in the range of experimental temperature, whereas that of Kamaboko $\mathrm{C}$ was somewhat lower. Temperature dependence of the breaking force and extent of the decrease in breaking force within the measuring temperature ranges, however, were almost the same in spite of the differences in the starch content. That is, breaking force decreased gradually with a rise in temperature, as well as dynamic modulus $G^{\prime 4}$ and instantaneous compression modulus. ${ }^{5)}$ According to Niwa et $a l{ }^{(1)}$ temperature dependence of the breaking force is quite different from present results as shown by a curve with a maximum temperature at about $30^{\circ} \mathrm{C}$ in the temperature range from 0 to $80^{\circ} \mathrm{C}$.

The breaking force and $G^{\prime}$ of Kamaboko are measured respectively under large and small deformation. They are different physical properties of Kamaboko. The temperature dependence of the breaking force of three different Kamaboko in the starch content, however, resembled each other, and comparable to $G^{\prime}$. Since the network structure of Kamaboko consists of chemical and physical bonds, the temperature dependence of these bonds appeared to function similarly even under large or small deformation. One main chemical bond which decreases in the force with rise in temperature might be hydrogen bond, ${ }^{7)}$ and is thought to play an important role in the network structure of Kamaboko. The breaking force of Kamaboko, however, was not necessarily lowered to near zero even at $80^{\circ} \mathrm{C}$, where hydrogen bonds can not function. Accordingly, some chemical or physical bonds in the network structure seemed to be stable at high temperatures. Namely, chemically stable bonds and physically strong entanglements are responsible for the stability of the network structure at high temperature.

\section{References}

1) S. Sato, T. Tsuchiya, and J. J. Matsumoto: Nippon Suisan Gakkaishi, 50, 1869-1876 (1984).

2) S. Nishimoto, A. Hashimoto, N. Seki, and K. Arai: Nippon Suisan Gakkaishi, 54, 1227-1235 (1988).

3) M. Nakamura: in "Denpun-Kagaku Handbook" (ed. by N. Nikuni), Asakura, Tokyo, 1979, pp. 185-192.

4) M. Hamada and Y. Inamasu: Nippon Suisan Gakkaishi, 50, 537-540 (1984).

5) N. Iso, H. Mizuno, T. Saito, F. Ohzeki, and N. Kurihara: Nippon Suisan Gakkaishi, 50, 10451049 (1984).

6) E. Niwa, E.-S. Chen, T.-T. Wang, S. Kanoh, and T. Nakayama: Nippon Suisan Gakkaishi, 54, 1789-1793 (1988).

7) E. Niwa, Y. Matsubara, and I. Hamada: Nippon Suisan Gakkaishi, 48, 667-670 (1982).

* Department of Food Science and Technology, Shimonoseki University of Fisheries, Nagata-honmachi, Shimonoseki, Yamaguchi 759-65, Japan (浜田盛承：水鷹大学校㹕造学科). 